\title{
Preliminarily comparative performance of removing bisphenol-S by ferrate oxidation and ozonation
}

\author{
Shaoqing Zhang $\mathbb{D}^{1}$, Jia-Qian Jiang (D) $^{1 凶}$ and Michael Petri ${ }^{2}$
}

Bisphenol-S (BS) has recently raised public concerns for its adverse effect on the health safety and ecological security. BS concentrations were detected in many water resources, ranging from $10 \mathrm{ng} \mathrm{L}^{-1}$ to $300 \mathrm{\mu g} \mathrm{L}^{-1}$, so that various purification techniques have been sought to remove BS. This study investigated the performance of ozonation and ferrate oxidation in the degradation of BS since they are both promising oxidants with high redox potential among water treatment chemicals. It was observed that both ozone and ferrate can achieve over $99 \%$ of BS concentration reduction and up to $22.5 \%$ of DOC reduction for dosing $0.036 \mathrm{mM}$ of either ferrate or ozone. The vibrio fisheri toxicity exhibited a decline in the treated samples after ozonation or ferrate oxidation. According to the mass spectra analyzed, the degradation pathways were proposed and oxidation products (OPs) were identified. BS degradation by ozonation and ferrate oxidation followed a similar route and four common OPs (OP-249; OP-497a; OP-497-b, and OP-201) were detected. While ferrate treatment produced one more intermediate (OP-217), ozonation did not, which is attributed to the intensified decomposition of BS by ozonation. The major impact of this study is that ferrate treatment is comparable to the ozonation in removing BS, and further research continuing from this study is necessary to explore the BS removal in various waters with more complex matrixes (e.g., high natural organic matter contents), to investigate BS degradation mechanisms in depth, and to conduct pilot-scale and full-scale trials to establish operational database in running ferrate oxidation and/or ozonation for the treatment of BS in practical world.

npj Clean Water (2021)4:1; https://doi.org/10.1038/s41545-020-00095-x

\section{INTRODUCTION}

Endocrine disrupting chemicals (EDCs) have received major public concerns in terms of their adverse effects on the water quality and public health. For human population exposed to EDCs, many endocrine-related diseases and disorders have been reported, for example, the incidence of genital malformations has increased over time at an unexpectedly high rate ${ }^{1,2}$. Bisphenol-A was once world widely used in industry but after its reorganization as one of $E D C s$, it has been phased out in the commercial use. Bisphenol-S (BS, or 4,4-sulfonyldiphenol) is then regarded as a safe replacement to bisphenol-A due to its higher thermal stability and proposed high biodegradability ${ }^{3-5}$, and has been widely used in the production of epoxy resins and also used as a chemical additive to produce colourfast agents, leather tanning agent, dye dispersants and fiber improvers ${ }^{6}$. However, based on fatal mouse tests, recent researches showed that BS exhibits high endocrine negative effect on human and aquatic species and the studies suggested that BS possesses higher toxicity than bisphenol-A and other bisphenol analogs $s^{3,4,7,8}$. In addition, BS concentrations were detected in a range from $10 \mathrm{ng} \mathrm{L}^{-1}$ to $300 \mathrm{\mu g} \mathrm{L}^{-1}$ in many water resources including raw water and waste water effluent ${ }^{9-11}$, which has caused concerns on the BS adverse effects on the aquatic environment and human health.

Several cleaning techniques have been tested for the removal of BS. For example, the activated sludge reactor and constructed wetland have shown high efficiency of removing BS but their performance was uncontrollable due to varying metabolisms when the ambient conditions changed ${ }^{12,13}$. The adsorptive technique can be considered as one of options, with $50-80 \%$ removal achievable but the optimized performance was achieved under relatively high restricted conditions ${ }^{14}$. Besides, many homogeneous and heterogeneous chemical oxidation techniques have been tested including the activated persulfate with $\mathrm{CuCO}_{2} \mathrm{SO}_{4}$ and permanganate coupled with iodide, which all show the acceptable performance in the removal of BS but with limitations ${ }^{15-17}$. And then, the alternative treatment technologies are still sought to tackle the BS pollution issues.

Ferrate $(\mathrm{Fe}(\mathrm{VI}))$ is a promising cleaning chemical for water and waste water treatment, which predominantly attributed to its high oxidation capacity and coagulation function after its rapid decomposition and dissociation in water ${ }^{18-20}$. The ferrate treatment is highly recommended due to its less adverse effect on human and ecosystems ${ }^{18,21}$, and has been studied to clean the $\mathrm{H}_{2} \mathrm{~S}$ odor, remove turbidity, color and heavy metals and to inactivate lethal bacteria ${ }^{22,23}$. Currently, the water treatment by ferrate is receiving more attention at the prospect of removing residuals of pharmaceuticals, EDCs and personal care products in water and waste water effluents ${ }^{18,19,24}$.

On the other hand, ozone is acknowledged as a strong reagent applied in water treatment ${ }^{25}$, which has greater oxidation capacity than permanganate, chlorine dioxide, chlorine gas, oxygen and hypochlorite ${ }^{26,27}$. As an oxidant in water treatment, ozone not only plays main role in disinfection ${ }^{27}$, but can react with unsaturated bonds and aromatic and amino groups and then degrade various organics $^{27,28}$. The mechanism of ozonation is the formation of various reactive oxygen species (ROS) and free radicals when ozone is decomposed, which hold fairly high redox potentials, especially the hydroxyl radical can exert maximum redox potential of $2800 \mathrm{mV}^{27}$. Table 1 shows the basic information of ferrate and ozone.

Due to the problematic issues caused by BS, this study aimed to conduct the comparative study of BS removal with ozonation and ferrate oxidation. Specifically, we investigated at bench scale, (1)

${ }^{1}$ Department of Civil Engineering and Environmental Management, Glasgow Caledonian University, Glasgow G4 0BA Scotland, United Kingdom. ${ }^{2}$ Qualitaetssicherung und Forschungslabor, Zweckverband Bodensee-Wasserversorgung, Suessenmuehle 1, 78354 Sipplingen, Germany. ${ }^{凶}$ email: jiaqian.jiang@gcu.ac.uk 
Table 1. Basic properties of ozone and ferrate potassium $26,27,36,37$.

\begin{tabular}{|c|c|c|}
\hline Parameters & Ozone & Ferrate \\
\hline Molecular formula & $\mathrm{O}_{3}$ & $\mathrm{~K}_{2} \mathrm{FeO}_{4}$ \\
\hline Oxidative species & $\begin{array}{l}\mathrm{O}_{3} \text { molecule } \\
\text { Free radicals generated as decomposition of ozone }\end{array}$ & $\begin{array}{l}\mathrm{FeO}_{4}^{2-} \\
\mathrm{HFeO}_{4}^{-} \text {and } \mathrm{H}_{2} \mathrm{FeO}_{4}\end{array}$ \\
\hline Reaction mechanism & $\begin{array}{l}\mathrm{O}_{3}+2 \mathrm{H}^{+} \rightleftarrows \mathrm{O}_{2(\mathrm{~g})}+\mathrm{H}_{2} \mathrm{O} \\
\mathrm{O}_{3}+\mathrm{HO}_{2}^{-} \rightarrow \mathrm{HO}_{2}^{\cdot}+\mathrm{O}_{3}^{-} \\
\mathrm{HO}_{2}^{\cdot} \rightarrow \mathrm{H}^{+}+\mathrm{O}_{2}^{-\cdot}\end{array}$ & $\begin{array}{l}\mathrm{H}_{3} \mathrm{FeO}_{4}{ }^{+} \rightleftarrows \mathrm{H}^{+}+\mathrm{H}_{2} \mathrm{FeO}_{4} \\
\mathrm{H}_{2} \mathrm{FeO}_{4} \rightleftarrows \mathrm{H}^{+}+\mathrm{HFeO}_{4}^{-} \\
\mathrm{HFeO}_{4}{ }^{-} \rightleftarrows \mathrm{H}^{+}+\mathrm{FeO}_{4}^{2-}\end{array}$ \\
\hline Redox potential (V) & $2.07-2.80$ & $0.7-2.2$ \\
\hline
\end{tabular}

Table 2. Comparative reduction of EDCs with ferrate oxidation and ozonation.

\begin{tabular}{|c|c|c|c|c|}
\hline \multicolumn{5}{|l|}{ Ferrate oxidation } \\
\hline EDC & Sample condition & Ferrate dosage & Removal (\%) & Reference \\
\hline Tetrabromobisphenol-A & $\begin{array}{l}\text { Deionised water } \\
0.018 \mathrm{mM}\end{array}$ & $0.025 \mathrm{mM}$ & 100 & 38 \\
\hline $17 \alpha$-ethinylestradiol (EE2) & $\begin{array}{l}\text { Deionized water } \\
0.01 \mathrm{mM}\end{array}$ & $0.05 \mathrm{mM}$ & 99 & 39 \\
\hline Bisphenol-A & $\begin{array}{l}\text { Deionised water } \\
0.002 \mathrm{mM}\end{array}$ & $0.002 \mathrm{mM}$ & $>95$ & 40 \\
\hline Octylphenol & $\begin{array}{l}\text { Natural water } \\
7.5 \mu \mathrm{M}\end{array}$ & $0.7 \mu \mathrm{M}$ & 100 & 41 \\
\hline Bisphenol-S & $\begin{array}{l}\text { Natural water } \\
10 \mu g \mathrm{~L}^{-1} \\
100 \mu \mathrm{g} \mathrm{L}-1\end{array}$ & $36 \mu \mathrm{M}$ & $\begin{array}{l}99.95 \\
99.99\end{array}$ & This study \\
\hline \multicolumn{5}{|l|}{ Ozonation } \\
\hline Chemicals & Sample condition & Ozone dosage & Removal (\%) & Reference \\
\hline Sulfolane & Spiked groundwater $20 \mathrm{mg} \cdot \mathrm{L}^{-1}$ & $200 \mathrm{mg} \cdot \mathrm{L}^{-1}$ & 82 & 42 \\
\hline \multirow[t]{2}{*}{ Bisphenol-A } & Spiked Milli-Q water 0.9 mg..$^{-1}$ & $1.4 \mathrm{mg} \cdot \mathrm{L}^{-1}$ & 99 & 43 \\
\hline & Spiked distilled water $0.509 \mathrm{mM}$ & $0.35 \mathrm{mM}$ & 87 & 44 \\
\hline levonorgestrel & $\begin{array}{l}\text { Spiked natural water } \\
2.3 \mu \mathrm{g} \cdot \mathrm{L}^{-1}\end{array}$ & $2 \mathrm{mg} \cdot \mathrm{L}^{-1}$ & 88 & 28 \\
\hline Bisphenol-S & $\begin{array}{l}\text { Natural water } \\
10 \mu \mathrm{g} \mathrm{L}^{-1} \\
100 \mu \mathrm{g} \mathrm{L}^{-1}\end{array}$ & $36 \mu \mathrm{M}$ & $\begin{array}{l}99.99 \\
99.99\end{array}$ & This study \\
\hline
\end{tabular}

the reduction of BS concentrations, (2) mineralization efficiency of BS, (3) resulting toxicity after the treatment, (4) the potential oxidation products (OPs) formation, and (5) the degradation pathways of BS, by ozonation and ferrate oxidation.

\section{RESULTS}

Reduction of BS concentration

Table 2 shows that the ozonation and ferrate oxidation both achieved the high BS reduction, together with removal efficiency of other EDCs by ferrate oxidation and ozonation. In this study, for its original concentrations of $10 \mu \mathrm{g} \mathrm{L}^{-1}$ and $100 \mu \mathrm{g} \mathrm{L}^{-1}$, respectively, BS was reduced $>99 \%$ by either ozonation or ferrate treatment for a chemical dose of $0.036 \mathrm{mM}$ at $\mathrm{pH}$ 7. The dose of $0.036 \mathrm{mM}$ of ferrate at $\mathrm{pH} 7$ was chosen for the comparison with the performance of ozonation since doses of ferrate greater than $0.036 \mathrm{mM}$ would not increase the BS reduction further (Supplementary Fig. 1) and neutral $\mathrm{pH}$ conditions produced similar BS reduction to that at the acidic condition but high reduction than that at the alkali condition (Supplementary Fig. 2).
Mineralization of BS (DOC removal)

DOC removal indicates the extent of mineralization of BS in water samples. Figure 1 shows that comparing to the concentration reduction of $\mathrm{BS}$, the $\mathrm{DOC}$ removal of $\mathrm{BS}$ was relatively lower; $17.2 \pm 1.91 \%$ and $22.5 \pm 1.93 \%$, respectively, by ozonation and ferrate treatment at a dose of $0.036 \mathrm{mM}$.

Toxicity assessment

Figure 2 shows the comparative toxicity in untreated BS samples and in the BS samples after treatment by ozonation and ferrate. The resulting toxicity of BS solution decreased after the treatment. It can be observed that the toxicity declined more with ferrate treatment compared with that by ozonation, the average resulting toxicity was reduced by $23 \%$ after ozonation and by $69 \%$ after ferrate treatment.

The toxicity results in this study were consistent to a reported study $^{29}$, where the resulting toxicity was significantly reduced after BS was treated by the peroxymonosulfate with the addition of Fe-SBA-15 under UV photolytic conditions. However, in another study ${ }^{16}$, the toxicity increased when decreasing in BS concentration after BS was treated by peroxydisulfate with sonolysis, suggesting the more toxic oxidation products were generated. 


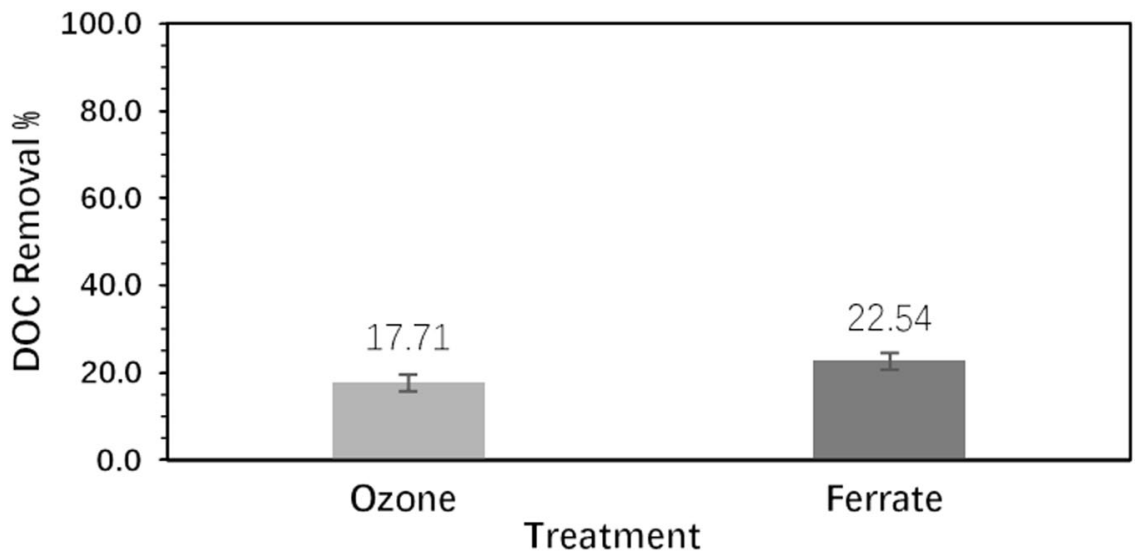

Fig. 1 DOC removal from BS spiked Lake Constance water with ozonation and ferrate treatment. [BS] $=1000 \mu \mathrm{gL}^{-1}$, $\mathrm{pH}=7$. The error bars inserted were based on the standard deviation (s.d., $n=3$ ).

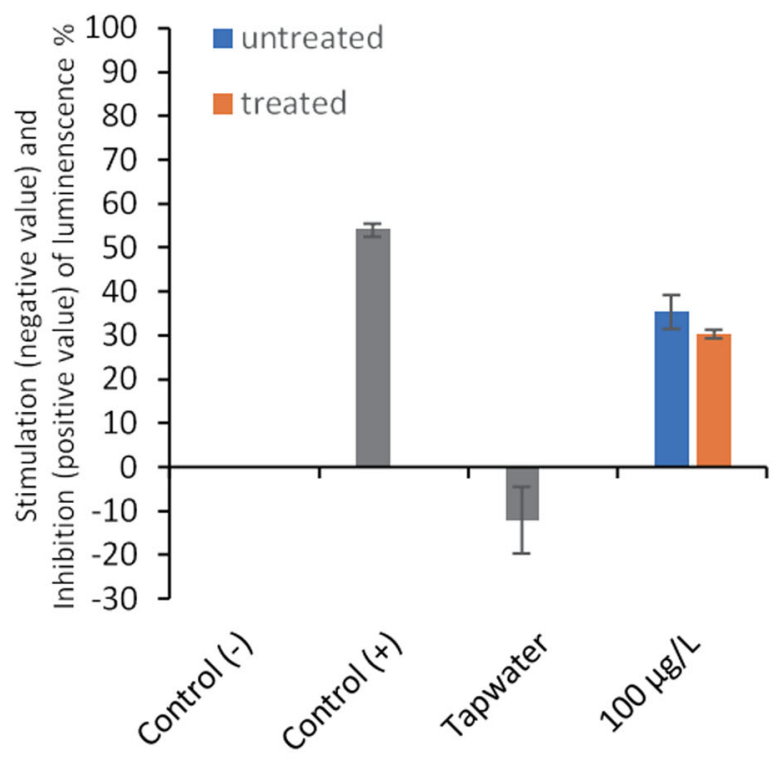

(a)

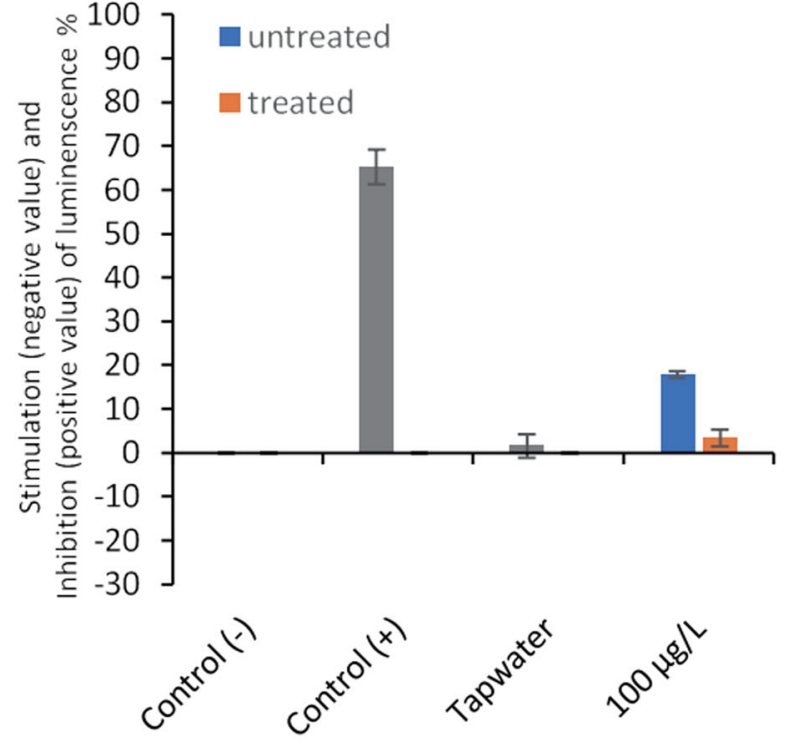

(b)

Fig. 2 Comparative toxicity of untreated and treated BS test solutions. $\mathrm{pH}=7$, The inhibition of luminescence $\%$ directly indicates the toxicity. a Ozone dose of $0.036 \mathrm{mM}$ and (b) ferrate dose of $0.036 \mathrm{mM}$. The errors bars inserted were based on standard deviation (s.d., $n=3$ ).

\section{Degradation pathways}

Figure 3 shows the detected OPs and the suggested degradation pathways of ozonation and ferrate treatment. The initial OP-1 $(\mathrm{m} / \mathrm{z}$ : 249), OP-2a ( $\mathrm{m} / \mathrm{z}: 497)$ and OP-2b ( $\mathrm{m} / \mathrm{z}$ : 497) were detected in the treated samples, which were also found in the previous studies $^{15,17,30}$. In degradation process, the hydroxylate group of BS was attacked by either ferrate or ozone, and two bisphenol-S groups were combined to form OPs-2a, 2b, which is one of common stages during the degradation, and OPs-2a, $2 \mathrm{~b}$ are consistent with that produced from other oxidation processes ${ }^{16,30}$. OP-4 ( $\mathrm{m} / \mathrm{z}:$ 201) was detected in the treated samples by both ferrate and ozone. It can be the partial cleavage of one aromatic ring but the second ring and sulphonyl group in BS remained. Figure 3 also shows that OP-4 could be derived directly from OP-1 ( $\mathrm{m} / \mathrm{z}$ : 249) and OP-2 ( $\mathrm{m} / \mathrm{z}: 497)$ in the processes of ozonation and ferrate oxidation, and indirectly from intermediate OP-3 ( $\mathrm{m} / \mathrm{z}: \mathrm{217})$ in the ferrate oxidation. Due to the relatively limited references linking to OP (4) compared to other OPs, the specific molecular structure and functional groups in OP (4) need to be investigated through further studies. Finally, the main routes of BS degradation pathways are similar in both ozonation and ferrate oxidation, however, one difference is that the intermediate OP-3 ( $\mathrm{m} / \mathrm{z}: 217)$ was detected only in the ferrate treated samples.

\section{DISCUSSION}

BS consists of phenol groups where both aromatic rings and hydroxylates are activated electron-rich moieties (ERMs) ${ }^{18,31}$. Therefore, ferrate and ozone can actively reacted with the abundant ERMs in the BS structures and thus a high BS degradation efficiency; greater than 99\% (Table 2). Properties of ozone and ferrate shown in Table 1 also explain high BS reduction achieved by the ozonation and ferrate treatment. Unlike catalytic ozonation system where substantial free radicals are generated, the oxygen molecules from ozone decomposition in this study acted as electron acceptors to capture the bonding electrons in the contaminant (BS). Likewise, under the study conditions, Fe ions in the ferrate anions (e.g., $\mathrm{HFeO}_{4}{ }^{-}$and $\mathrm{FeO}_{4}{ }^{2-}$ ) have high oxidation numbers which act as electron-acceptors too, then ferrate anions can captures the chemical bonding electrons of BS. 


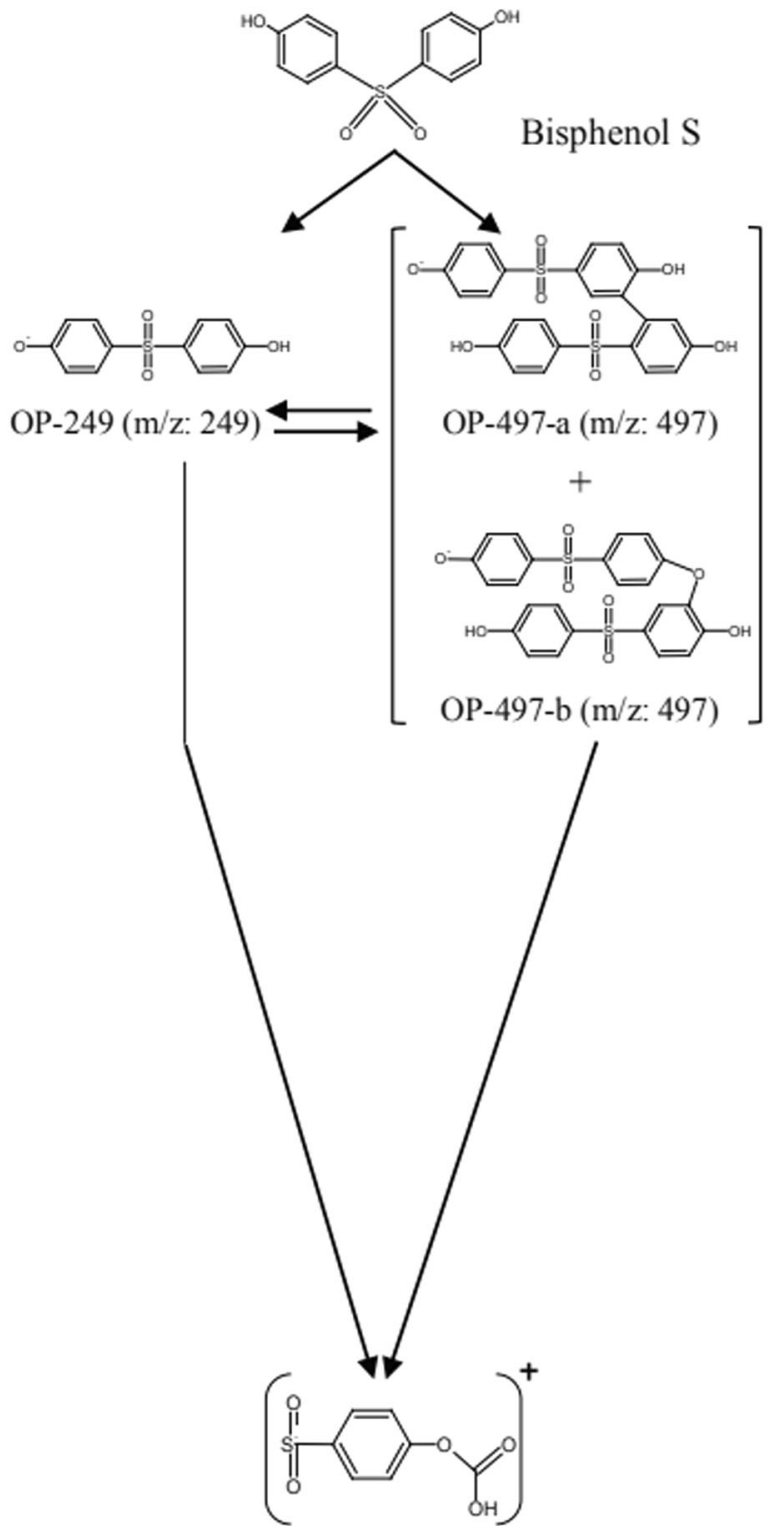

OP-201 (m/z: 201)

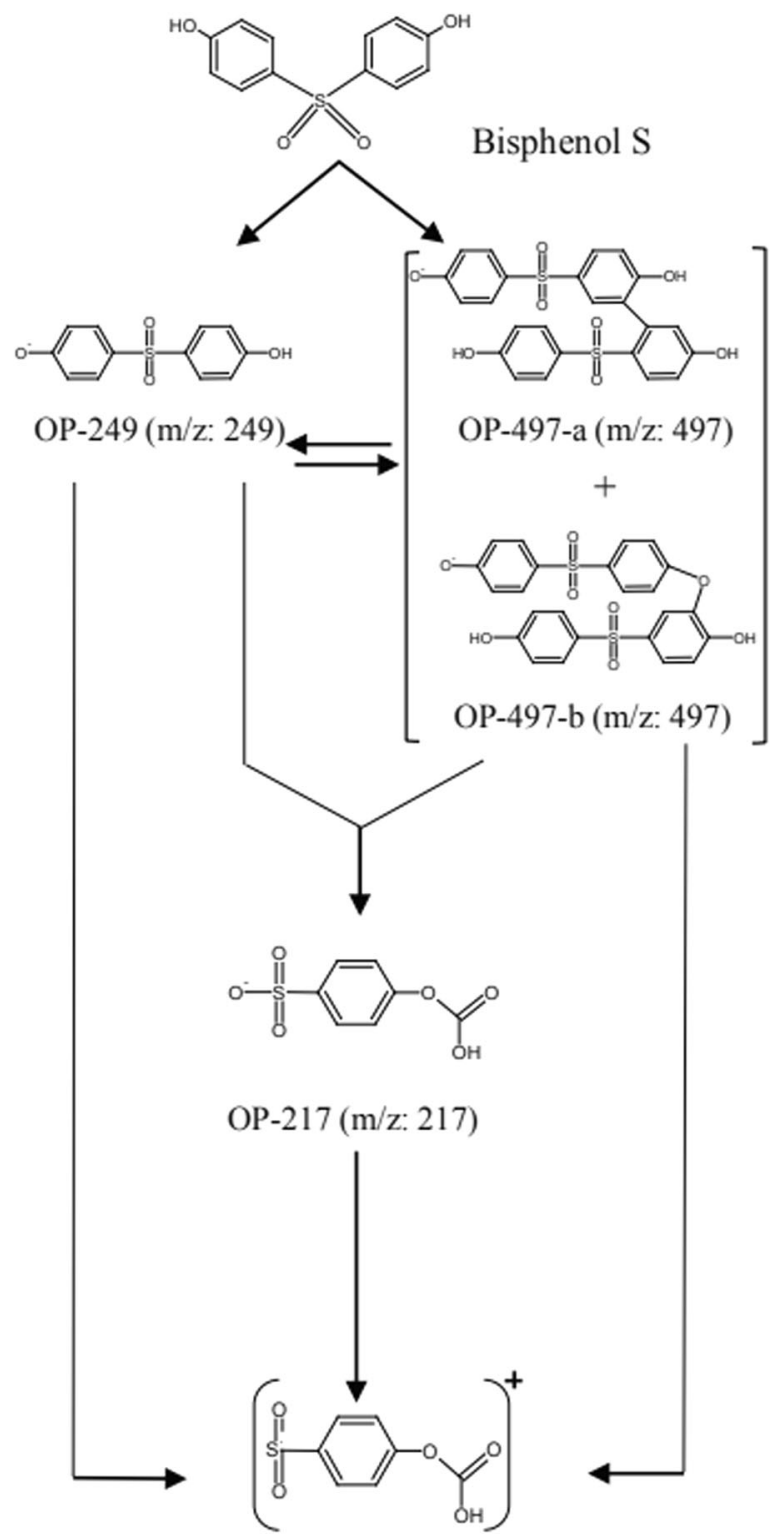

OP-201 (m/z: 201)

(a)

(b)

Fig. 3 BS degradation pathways. a Ozonation process and (b) ferrate treatment.

As shown in Table 2, as well as BS, other selected endocrine disrupting chemicals (EDCs) with ERMs groups were reduced their concentrations greatly (at least $>95 \%$ ) by the reaction with ferrate and ozone, suggesting that the proposed electron-capturing by either ozone molecules/free radicals or ferrate species plays predominate role in the treatment of ERMs' abundant EDCs.

However, the mineralization of BS or DOC reduction was lower than the reduction of BS concentration, suggesting the formation of substantial oxidation products (OPs) in the processed samples. The slightly higher BS mineralization (DOC reduction) by ferrate compared with that by ozonation (Fig. 1) could be attributed to the additional ferric coagulation, which was simultaneously occurred when ferrate was decomposed to water. The declined toxicity after treatment (Fig. 2) suggests that the BS degradation derived OPs had lower toxicity comparing to the BS itself. Lower toxicity after ferrate treatment was achieved in comparison with that after ozonation and this is most likely due to the formation of bromated-halogenated derivatives produced in ozonation when bromide was presented in water ${ }^{32}$ (Table S2). Instead, ferrate barely reacts with bromide ions thus averting the critical formation of potential carcinogenic bromate and other halogenated by-products such as trihalomethanes $(\mathrm{THM})^{33}$. The formation of OPs in both ferrate treatment and ozonation was detected in this study (Fig. 3) and the BS degradation pathways were proposed as shown in above. Interestingly, OP-217 was not presented in the ozonated samples (Fig. 3) and this can be attributed to the higher re-dox potential of ozone, which resulted in the intensified cleavage rate of heterocyclic group in the stated intermediate OP-217. For supporting this explanation, though, further studies are required. When the toxicity and adverse environmental effect of BS have been recognized and the potential treatment techniques are sought to tackle the BS 


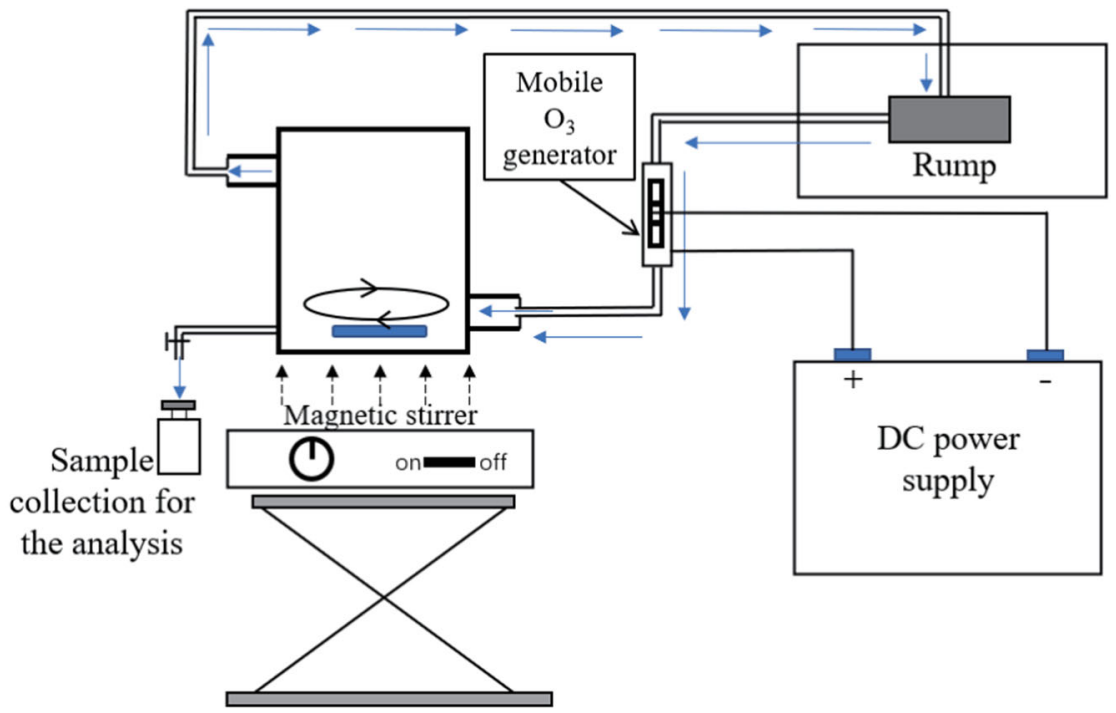

Fig. 4 Schematic ozonation reactor. Schematic ozonation reactor.

\begin{tabular}{|llll|}
\hline Table 3. BS test solutions and preparation. & & & \\
\hline Target BS concentration in the reactor $\left(\mu \mathrm{g} \mathrm{L}^{-1}\right)$ & Stock concentration $\left(\mathrm{mg} \mathrm{L}^{-1}\right)$ & Spiked volume $(\mathrm{mL})$ & Final test solution volume $(\mathrm{mL})$ \\
\hline 10 & 20 & 0.125 & 250 \\
100 & 20 & 1.25 & 250 \\
1000 & 20 & 12.5 & 250 \\
\hline
\end{tabular}

pollutions, the major impact of this study is that ferrate is comparable to the ozonation in the treatment of BS presenting in water, and the performance of ferrate was even better than ozonation, such as low residual toxicity in the treated samples. Further research continuing from this study is necessary to explore BS removal in various waters with more complex matrixes (e.g., high natural organic matter contents), to investigate BS degradation mechanisms in depth, and to conduct pilot-scale and fullscale trials to establish operational database in running ferrate for the treatment of BS in practical world.

\section{METHODS}

Materials

BS (98\%), $\mathrm{NaCl}(99 \%)$, potassium ferrate and $98 \%$ potassium dichromate $\left(\mathrm{K}_{2} \mathrm{Cr}_{2} \mathrm{O}_{7}\right)$ were purchased from Sigma-Aldrich (Germany). Reagent $\mathrm{A} 1$ (buffer solution), reagent $\mathrm{A} 2$ ( $\mathrm{N}$-diethyl-p-phenylenediamine) and reagent B (potassium iodide) for DPD method were purchased from the Innovate Geraetetechnik GmbH Rheinbach, Germany. Deionized water was supplied by the Milli- $Q^{\text {TM }}$ Ultrapure Water Purification System. $20 \mathrm{mg} \mathrm{L}^{-1}$ stock solution of BS were prepared by deionized water. Luminescent bacteria were stored in the freezer at $-15^{\circ} \mathrm{C} .2 \% \mathrm{NaCl}$ (negative control reference) and $20 \% \mathrm{NaCl}$ solution were prepared with $99 \% \mathrm{NaCl}$ and deionized water. Positive control reference stock solution $\left(1.87 \mathrm{~g} \mathrm{~L}^{-1} \mathrm{Cr}^{6+}\right)$ was prepared with $98 \% \mathrm{~K}_{2} \mathrm{Cr}_{2} \mathrm{O}_{7}$ and deionized water.

Preparation of ozonation reactor and ferrate treatment and procedures

Mobile ozone generator with 3 micro cells ELEK 4.4 and DC power supply device were purchased from Innovate Geraetetechnik $\mathrm{GmbH}$ Rheinbach, Germany. The calibration of ozone concentration was conducted based on the Supplementary Method 1. Peristaltic pump (Heidoph Pump drive 5001) was applied for loading lake water into the circulation system (Fig. 4 and Supplementary Table 1), the quality of lake water can be viewed in Supplementary Table 2. IKA IKAMAG combing RCT heated magnetic stirrer
Table 4. Coagulation mixing mode as a simulation of practical condition.

\begin{tabular}{lll}
\hline Mixing mode & Time $(\mathrm{min})$ & Mixing intensity $(\mathrm{rpm})$ \\
\hline Fast & 2 & 250 \\
Slow & 20 & 40 \\
Sedimentation & 120 & N/A \\
\hline
\end{tabular}

was used for mixing the water at the required rate. When the ozone concentration reached to $0.03 \mathrm{mM}\left(2 \mathrm{mg} \mathrm{L}^{-1}\right)$ (tested by DPD colorimetric method in Supplementary Method 2), ozone generation was stopped and the given volume of BS stock solution (Table 3 ) was spiked into the ozone saturated lake water to start the reaction. After $15 \mathrm{~min}$ ozonation, the reaction was quenched by either adding $0.1 \mathrm{~mL}$ of $0.1 \mathrm{M}$ thiosulphate or the injection of nitrogen gas for $4 \mathrm{~min}$. Each test was triplicated. The nitrogen-gas quenched samples were collected for LC-MS analysis, and the thiosulphate quenched samples were collected for DOC analysis.

The strength of the purchased ferrate $\left(\mathrm{K}_{2} \mathrm{FeO}_{4}\right)$ was determined using the UV-vis spectrometric method at $505 \mathrm{~nm}$ and calculated by Eq. (1), and it was $23 \%$. The ferrate working solutions were freshly prepared before the experiment; $324.64 \mathrm{mg} \mathrm{K}_{2} \mathrm{FeO}_{4}$ was mixed with $0.005 \mathrm{M} \mathrm{NaOH}$ solution to make a total of $5 \mathrm{~mL}$ of ferrate working solution at concentration of $4.0 \mathrm{~g}$ $\mathrm{Fe} \mathrm{L}^{-1}$. To achieve the required ferrate doses, $0.4 \mathrm{~mL}$ of the stated ferrate working solution was dosed into $800 \mathrm{~mL}$ of the test sample to achieve $\mathrm{Fe}$ (Vl) dose of $0.036 \mathrm{mM}$.

Molar concentration $\left(\mathrm{Fe}^{6+}\right)=\frac{\text { UV abs of Ferrate solution }(\lambda=505 \mathrm{~nm})}{1150}$

A $10 \mu \mathrm{g} \mathrm{L}^{-1}$ and $100 \mu \mathrm{gL}^{-1}$ of BS test solutions were prepared by pipetting $1 \mathrm{~mL}$ and $10 \mathrm{~mL}$ of $20 \mathrm{mg} \mathrm{L}^{-1}$ of each stock solution respectively, into $2 \mathrm{~L}$ volumetric flasks and added up to $2 \mathrm{~L}$ with lake water; three magnetic stirrers were used for the jar tests. The stated volume of ferrate working solution was dosed into the pre-prepared $10 \mathrm{\mu g} \mathrm{L}^{-1}$ and $100 \mathrm{\mu g} \mathrm{L}^{-1}$ test solutions. The mixing programming was set up as shown in Table 4. 


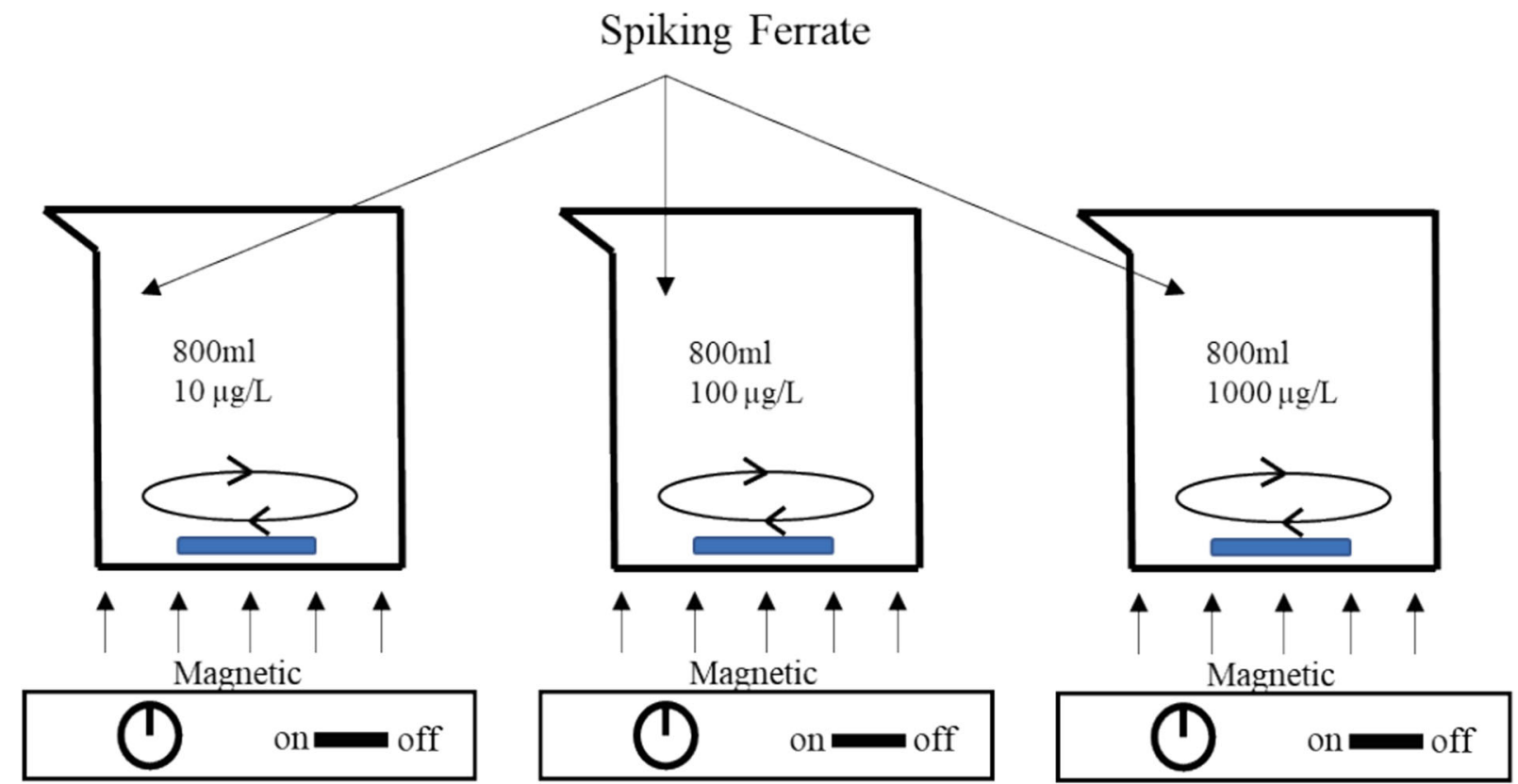

Fig. 5 Schematic jar test facilities used for ferrate treatment. Schematic jar test facilities used for ferrate treatment.

The device setup can be seen in Fig. 5. Treated samples were filtered through $0.45 \mu \mathrm{m}$ cellulose filter disc with Sartorius Stedim Borosilicate Glass Vacuum Filtration device and filtered samples were collected for analyzing the BS concentration by LC-MS and TOC by the TOC analyzer. Each jar test was triplicated.

\section{Bio-luminescence toxicity test}

The bioluminescent toxicity test was conducted according to International Standard ISO 11348-3:2007(E) $)^{34}$. All untreated and treated samples were prepared with $20 \% \mathrm{NaCl}$ to make up to $2 \%$ salinity. Vibrio fischeri bacteria were rehydrated and evenly shaken with reactivation reagent, the reactivated bacteria solution were stored in the refrigerator for 30 mins under temperature between $2{ }^{\circ} \mathrm{C}$ and $8{ }^{\circ} \mathrm{C}$ for the purpose of stabilization. The experiment was conducted following the protocols of ISO 113483:2007 (E). All test samples were prepared three times, and the toxicity test of each sample was triplicated. The results were calculated by adapting the protocol of ISO 11348-3 as shown in Eq. (2)

$$
\operatorname{inh} \%=\left(\frac{I_{30}-I_{30}}{I_{30}}\right) \times 100 \quad I_{C 30}=10 \times f_{k 30} \quad f_{k 30}=\frac{l_{k 30}}{I_{0}}
$$

Where the inh\% in Eq. 2 denotes the inhibition of luminescence. $f_{k 30}$ is the correction factor controlling for the natural attenuation of luminescence, which is based on the negative control $\left(2 \% \mathrm{NaCl}\right.$ solution). $l_{30}$ is the actual luminescence intensity after adding the test sample for $30 \mathrm{~min}, 10$ is the luminescence intensity before adding the test sample, $\mathrm{I}_{0}$ is the initial luminescence reading of the negative control without adding test sample, and $I_{k 30}$ is the luminescence reading of the negative control after adding test sample for $30 \mathrm{~min}$. $\mathrm{I}_{\mathrm{c} 30}$ is the initial luminescence reading corrected with consideration of effect by time. The tests were validated based on the ISO 11348-3:2007 (E); the correction factors $\mathrm{f}_{\mathrm{k} 30}$ in this study distribute among range between 0.6 and 1.8 , and the inhibition (ihn\%) of positive control $\left(5.29 \mathrm{~g} \mathrm{~L}^{-1} \mathrm{~K}_{2} \mathrm{Cr}_{2} \mathrm{O}_{7}\right.$ in $2 \% \mathrm{NaCl}$ solution) was in the range from 20 to $80 \%$.

\section{Analytical technology}

DOC in samples was measured by Elementar Vario TOC analyzer. The measurement was conducted when the temperature of the combustion tube reached $850^{\circ} \mathrm{C}$, the loading gas flow was $200 \mathrm{~mL} \mathrm{~min}^{-1}$. The liquid chromatographic mass spectro-meter (LC-MS) employed was Thermo Scientific Q-Exactive Orbital-trap mass spectrometer with Accela 1200 LC and Acquity HSS T3 column $(2.1 \times 100 \mathrm{~mm}, 1.8 \mu \mathrm{m})$. The mobile phase was a gradient mixture of solvent $A$ and solvent $B$ : solvent $A$ was made of $0.05 \%$ formic acid in MilliQ water, and solvent $B$ was made of $0.05 \%$ formic acids in HPLC-grade methanol. For the analysis of $\mathrm{BS}$ concentration, the equilibration started with elution of $95 \%$ solvent $A$ and $5 \%$ solvent $B$ at flow rate of $0.3 \mathrm{~mL} \mathrm{~min}{ }^{-1}$ for
$0.25 \mathrm{~min}$. Then, elution of solvent A started decrease till reached to $20 \%$ with solvent B increased to $80 \%$ at $6 \mathrm{~min}$, and this elution remained constant shortly till 6.95 min. Finally, the solvent A rapidly increased to $95 \%$ with solvent B dropped to $5 \%$ till whole elution completed at $10 \mathrm{~min}$. The injection volume of sample was $100 \mu \mathrm{L}$, and the overall running time was $10 \mathrm{~min}$. The detected retention time of bisphenol-S was approximately $6.43 \mathrm{~min}$. The monoisotopic mass of the protonated molecular ion of $\mathrm{BS}$ was 251.0372 and one identifying fragment of BS in mass spectra was $156.9953\left(\mathrm{C}_{6} \mathrm{H}_{5} \mathrm{O}_{3} \mathrm{~S}\right)$. The BS analytical method was validated; the standard recoveries were $85-125 \%$ which meets the acceptable range ${ }^{35}$, and the spiking standard concentrations used to establish recovery percentages were $5,15,30,50$, and $300 \mathrm{\mu g} \mathrm{L}^{-1}$, respectively. In addition, the detection limit for BS was set up as $25 \mathrm{ng} \mathrm{L}^{-1}$, the limit of quantification was $25 \mathrm{ng} \mathrm{L}^{-1}$, and the total instrumental run-time of analysis per one batch of samples was $6 \mathrm{~h}$.

\section{DATA AVAILABILITY}

All data generated in the study are presented in this communication and/or the Supplementary Information. Additional data related to this paper may be requested from the authors.

Received: 25 August 2020; Accepted: 2 December 2020; Published online: 04 January 2021

\section{REFERENCES}

1. Bergman Å., Heindel J. J., Jobling S., Kidd K., \& Zoeller T. R. World Health Organization. State of the Science of Endocrine-disrupting Chemicals 2012. (World Health Organization, 2013).

2. Diamanti-Kandarakis, E. et al. Endocrine-disrupting chemicals: an Endocrine Society scientific statement. Endocr. Rev. 30, 293-342 (2009).

3. Eladak, S. et al. new chapter in the bisphenol A story: bisphenol $\mathrm{S}$ and bisphenol $\mathrm{F}$ are not safe alternatives to this compound. Fertil. Steril. 103, 11-21 (2015).

4. Ike, M., Chen, M. Y., Danzl, E., Sei, K. \& Fujita, M. Biodegradation of a variety of bisphenols under aerobic and anaerobic conditions. Water Sci. Technol. 53, 153-159 (2006)

5. Žalmanová, T. et al. Bisphenol $\mathrm{S}$ instead of bisphenol A: a story of reproductive disruption by regretable substitution-a review. Czech J. Anim. Sci. 61, 433-449 (2016).

6. Cao, G., Lu, J. \& Wang, G. Photolysis kinetics and influencing factors of bisphenol $S$ in aqueous solutions. J. Environ. Sci. 24, 846-51 (2012).

7. Héliès-Toussaint, C., Peyre, L., Costanzo, C., Chagnon, M. C. \& Rahmani, R. Is bisphenol $\mathrm{S}$ a safe substitute for bisphenol $\mathrm{A}$ in terms of metabolic function? An in vitro study. Toxi. Appl. Pharma. 15, 224-235 (2014). 
8. Ahsan, N., Ullah, H., Ullah, W. \& Jahan, S. Comparative effects of Bisphenol S and Bisphenol $\mathrm{A}$ on the development of female reproductive system in rats; a neonatal exposure study. Chemosphere 197, 336-343 (2018).

9. Ebele, A. J., Abdallah, M. A. \& Harrad, S. Pharmaceuticals and personal care products (PPCPs) in the freshwater aquatic environment. Emerg. Contaminant. 3, 1-6 (2017).

10. Yamazaki, E. et al. Bisphenol A and other bisphenol analogues including BPS and BPF in surface water samples from Japan, China, Korea and India. Ecotoxicol. Environ. Saf. 122, 565-572 (2015).

11. Wan, Y. et al. Spatial distribution of bisphenol $S$ in surface water and human serum from Yangtze River watershed, China: Implications for exposure through drinking water. Chemosphere 199, 595-602 (2018).

12. Huang, W. C., Jia, X. F., Li, J. Y. \& Li, M. Dynamics of microbial community in the bioreactor for bisphenol S removal. Sci. Total Environ. 662, 15-21 (2019).

13. Wirasnita, R., Mori, K. \& Toyama, T. Effect of activated carbon on removal of four phenolic endocrine-disrupting compounds, bisphenol A, bisphenol F, bisphenol S, and 4-tert-butylphenol in constructed wetlands. Chemosphere 210, 717-725 (2018).

14. Al-Mashhadani S. A. Adsorption of Bisphenol-s (BPS) from Water Using Activated Carbon. MSc thesis. University of Dayton (2017).

15. $\mathrm{Xu}, \mathrm{H}$. et al. A superior active and stable spinel sulfide for catalytic peroxymonosulfate oxidation of bisphenol S. Appl. Catal. B 238, 557-567 (2018).

16. Lu, X. et al. Sonolytic degradation of bisphenol S: effect of dissolved oxygen and peroxydisulfate, oxidation products and acute toxicity. Water Res. 165, 1149-1169 (2019).

17. Li, J. et al. Transformation of bisphenol AF and bisphenol $\mathrm{S}$ by permanganate in the absence/presence of iodide: kinetics and products. Chemosphere 217, 402-410 (2019).

18. Jiang, J.-Q. Advances in the development and application of ferrate(VI) for water and wastewater treatment. J. Chem. Technol. Biotechnol. 89, 165-177 (2014).

19. Zhou, Z. \& Jiang, J.-Q. Treatment of selected pharmaceuticals by ferrate(VI): performance, kinetic studies and identification of oxidation products. J. Pharm Biomed. Anal. 106, 37-45 (2015).

20. Gombos, E. et al. Removal of organic matters in wastewater treatment by ferrate (VI)-technology. Microchem J. 107, 115-120 (2013).

21. Jiang, J.-Q. \& Lloyd, B. Progress in the development and use of ferrate(VI) salt as an oxidant and coagulant for water and wastewater treatment. Water Res. 36 , 1397-1408 (2002).

22. Jiang, J.-Q., Wang, S. \& Panagoulopoulos, A. The exploration of potassium ferrate (VI) as a disinfectant/coagulant in water and wastewater treatment. Chemosphere 63, 212-219 (2006)

23. Jiang, J.-Q. Research progress in the use of ferrate $(\mathrm{VI})$ for the environmental remediation. J. Hazard. Mater. 146, 617-623 (2007).

24. Jiang, J.-Q., Yin, Q., Zhou, J. L. \& Pearce, P. Occurrence and treatment trials of endocrine disrupting. Chem. Wastewaters Chemo. 61, 544-550 (2005).

25. Loeb, B. L., Thompson, C. M., Drago, J., Takahara, H. \& Baig, S. Worldwide ozone capacity for treatment of drinking water and wastewater: a review. Ozone $\mathbf{3 4}$ 64-77 (2012).

26. Blaney, L. Ozone treatment of antibiotics in water. In Water Reclamation and Sustainability. 265-316, Editor: Satinder Ahuja (Elsevier, 2014).

27. Gunten, U. Ozonation of drinking water: Part I. Oxidation kinetics and product formation. Water Res. 37, 1443-1467 (2003).

28. Broséus, R. et al. Ozone oxidation of pharmaceuticals, endocrine disruptors and pesticides during drinking water treatment. Water Res. 43, 4707-4717 (2009).

29. Rahmani, A., Rahimzadeh, H., Samadi, M. T., Farmani, A. \& Asgari, G. Bisphenol S degradation using Fe-SBA-15/UV/US/peroxymonosulfate: performance optimization, biodegradability, mineralization and toxicity studies. Des. Water Treat. 163 297-309 (2019)

30. Wang, Q. et al. Degradation of Bisphenol S by heat activated persulfate: kinetics study, transformation pathways and influences of co-existing chemicals. Chem. Eng. J. 328, 236-245 (2017).

31. Lee, Yvon \& Gunten, U. Oxidative transformation of micropollutants during municipal wastewater treatment: comparison of kinetic aspects of selective (chlorine, chlorine dioxide, ferrate $\mathrm{Vl}$, and ozone) and non-selective oxidants (hydroxyl radical). Water Res. 44, 555-566 (2010)

32. Haag, W. R. \& Hoigne, J. Ozonation of bromide-containing waters: kinetics of formation of hypobromous acid and bromate. Environ. Sci. Technol. 17, 261-267 (1983).

33. Zhang, M. S., Xu, B., Wang, Z., Zhang, T. Y. \& Gao, N. Y. Formation of iodinated trihalomethanes after ferrate pre-oxidation during chlorination and chloramination of iodide-containing water. J. Taiwan Instit. Chem. Eng. 60, 453-459 (2016).

34. ISO D. 11348-3. Water Quality—determination of the Inhibitory Effect of Water Samples on the Light Emission of Vibrio Fischeri (Luminescent Bacteria Test)_part 3: Method Using Freeze-dried Bacteria. (International Organization for Standardization, 2007)

35. Jenke, D. et al. Development and validation of chromatographic methods for the identification and quantitation of organic compounds leached from a laminated polyolefin material. J. Chromatographic Sci. 42, 388-395 (2004).
36. Sharma, V. K., Rivera, W., Smith, J. O. \& O'Brien, B. Ferrate (VI) oxidation of aqueous cyanide. Environ. Sci. Technol. 32, 2608-2613 (1998).

37. Graham, N., Jiang, C. C., Li, X. Z., Jiang, J.-Q. \& Ma, J. The influence of pH on the degradation of phenol and chlorophenols by potassium ferrate. Chemosphere 56, 949-956 (2004)

38. Han, Q. et al. Degradation of tetrabromobisphenol A by ferrate (VI) oxidation: performance, inorganic and organic products, pathway and toxicity control. Chemosphere 198, 92-102 (2018).

39. Li, C., Li, X. Z., Graham, N. \& Gao, N. Y. The aqueous degradation of bisphenol A and steroid estrogens by ferrate. Water Res. 42, 109-120 (2008).

40. Yang, B. et al. Ferrate ( $\mathrm{VI})$ oxidation of tetrabromobisphenol $\mathrm{A}$ in comparison with bisphenol A. Water Res. 62, 211-219 (2014).

41. Anquandah, G. A. \& Sharma, V. K. Oxidation of octylphenol by ferrate (VI). J. Environ. Sci. Heal. Part A. 44, 62-66 (2009).

42. Khan, M. F., Yu, L. \& Achari, G. Field evaluation of a pressurized ozone treatment system to degrade sulfolane in contaminated groundwaters. J. Environ. Chem. Eng. 8, 104037 (2020).

43. Umar, M., Roddick, F., Fan, L. \& Aziz, H. A. Application of ozone for the removal of bisphenol A from water and wastewater-a review. Chemosphere 90, 2197-2207 (2013).

44. Kusvuran, E. \& Yildirim, D. Degradation of bisphenol A by ozonation and determination of degradation intermediates by gas chromatography-mass spectrometry and liquid chromatography-mass spectrometry. Chem. Eng. J. 220, 6-14 (2013)

\section{ACKNOWLEDGEMENTS}

The authors are grateful to Glasgow Caledonian University and German Lake Constance Water Supply for offering a studentship to Mr. S. Zhang for his PhD study. Also, we thank German Lake Constance Water Supply for their sponsorship for this field research. Special thanks go to Christian Mosbach and other staff at the water company's laboratory for their support when running the trials. The views expressed in this paper are not necessary representing those from the water company.

\section{AUTHOR CONTRIBUTIONS}

All authors have contributions to the conception and design of the work, analysis of the data, and drafting the work. J.-Q.J. gained the research funding, supervised the work, and provided extensive contributions to the preparation of the final version of the manuscript.

\section{COMPETING INTERESTS}

The authors declare no competing interests.

\section{ADDITIONAL INFORMATION}

Supplementary information is available for this paper at https://doi.org/10.1038/ s41545-020-00095-x.

Correspondence and requests for materials should be addressed to J.-Q.J.

Reprints and permission information is available at http://www.nature.com/ reprints

Publisher's note Springer Nature remains neutral with regard to jurisdictional claims in published maps and institutional affiliations.

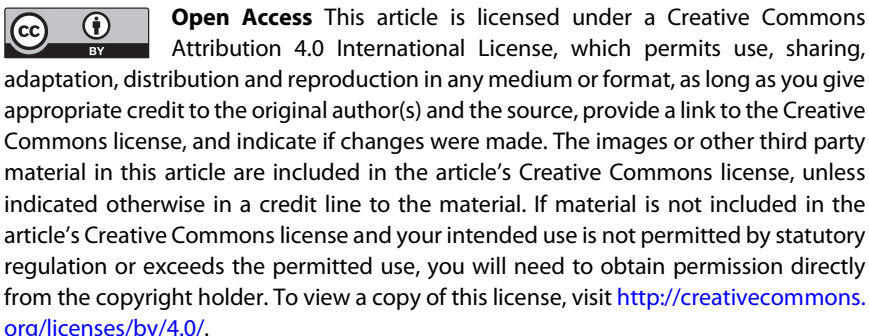

(c) The Author(s) 2021, corrected publication 2021 